\title{
Supply Chain Flexibility Evaluation Based on Matter-Element Extension
}

\author{
Xiaochun Luo $\mathbb{D D}^{1,2}{ }^{1,2}$ Zilong Wang, ${ }^{1}$ Lin $\mathrm{Lu} \mathbb{D},{ }^{2}$ and Yan Guan ${ }^{2}$ \\ ${ }^{1}$ College of Economics and Management, Nanjing University of Aeronautics and Astronautics, Nanjing, China \\ ${ }^{2}$ College of Economics and Management, Guangxi Normal University, Guilin, China \\ Correspondence should be addressed to Lin Lu; lulin355@163.com
}

Received 27 March 2020; Revised 4 May 2020; Accepted 7 May 2020; Published 20 May 2020

Academic Editor: Abdelalim Elsadany

Copyright (C) 2020 Xiaochun Luo et al. This is an open access article distributed under the Creative Commons Attribution License, which permits unrestricted use, distribution, and reproduction in any medium, provided the original work is properly cited.

Flexibility is an important indicator to consider the uncertain information processing ability of the supply chain comprehensively. It is a powerful way to improve the efficiency and quality of supply chain operation by evaluating the level of supply chain flexibility effectively. The traditional method is used to decompose the supply chain flexibility evaluation indicators from the perspective of system structure or cost saving, but these indicators cannot truly describe the dynamics of the supply chain operation. Otherwise, supply chain flexibility evaluation is a typical multiobjective evaluation; there are some incompatibilities between these flexible evaluation indicators, and the common evaluation methods are difficult to deal with such contradictions. In this paper, the dynamic characteristics of supply chain operation are considered, and the evaluation system of supply chain flexibility is designed from the perspective of operation efficiency. The matter-element analysis theory is used to create the comprehensive appraisal model of supply chain flexibility. The matter-element matrix solves the uncertainty and incompatibility of the evaluated factors used to assess supply chain flexibility. The paper evaluates the performance of four autoservice companies and concludes that the evaluation grades of the four companies are in line with the reality, indicating that the evaluation system and the method are effective and credible.

\section{Introduction}

Internet information technology has promoted tremendous changes in the functions and roles of market participants. Consumers have gradually replaced producers and enterprises as the main force of economic operation, which is the core force of promoting production and market reform. Under the influence of information technology, the consumer market environment has distinct characteristics of the times: diversification, speediness, individuation, and to a greater extent, it is easy to be influenced by the herd effect. Unpredictable changes in the market environment increase the risk of business operation and investment, so the "horizontal integration" mode of thinking came into being, that is, for the flow of logistics, capital flow, information flow, and other elements among enterprises in the supply chain, to carry out efficient, integrated, seamless, real-time, and effective management, so as to promote the organic cooperation between enterprises and enhance the competition of the whole supply chain strive to maximize the performance of the whole supply chain. The uncertainty of the market environment and the existence of risk factors make the supply chain enterprises to respond to the unexpected situation of market environment quickly. Supply chain flexibility is an important tool for dealing with uncertain information. Improving the level of supply chain flexibility plays a very positive role in improving the overall operation efficiency of the supply chain and maintaining the core competitiveness of the enterprise. It is an important way to improve the operation quality of the supply chain.

In the supply chain management environment, flexibility refers to the ability of supply chain managers to quickly and effectively reconfigure the internal supply chain in order to adapt to the changing market demand, so as to cope with the uncertainty of the internal and external environment $[1,2]$. With the increasing dynamic and uncertainty of business environment and the shortening of product life cycle, the ability to respond quickly to changes becomes more and 
more important for core enterprises and the whole supply chain [3]. Supply chain flexibility can not only show the ability of quick response to environmental changes but also has a certain strategic role [4], such as helping enterprises to make profits and meet customers' changing needs [5].

The research on the dimensions of the supply chain flexible system mainly includes the dimensions of supply flexibility and manufacturing flexibility [6], process flexibility and holding product inventory [7], flexible structure deployment information technology [8], supply chain contract [9], order fulfillment flexibility [10], and operation and organization absorption flexibility [11]. The evaluation indicators of supply chain flexibility are diversified. From the perspective of performance, they are divided into four primary indicators: supply chain re-engineering flexibility, supply chain collaboration flexibility, supply chain flexibility, and the establishment of supply chain risk management culture [12]. From the perspective of supply chain agility, they can be divided into 25 evaluation indicators such as organizational structure flexibility, production flexibility, market scheduling flexibility, quality control flexibility, organizational flexibility, operation flexibility, customer service flexibility, organizational structure flexibility, effective prediction flexibility, and logistics management flexibility [13], or they can be divided into 22 evaluation indicators, such as supplier flexibility, coordination flexibility among supply chain members, fast response ability, fast conversion ability, information transparency, design flexibility, production and delivery flexibility, labor flexibility, quality level, innovation degree, etc. [14]. From the perspective of organizational hierarchy, they can be divided into operational flexibility (workshop and resource level) [15], strategic flexibility (company level) [16], tactical flexibility (plant level) [17], and supply chain flexibility (network level) [18]. It is impossible to measure the flexibility of the whole supply chain by a single standard. An analysis method [19] that can evaluate the flexibility of the supply chain comprehensively and continuously is needed, such as AHP [20] and sensitivity analysis [21].

Most of the existing literature mainly focus on the supply chain model, supply chain integration, supply chain flexibility measurement, supply chain flexibility strategic level planning, and tactical level implementation and rarely involve the coexistence of incompatible indicators in the supply chain flexibility evaluation, as well as the integration of qualitative and quantitative evaluation; in addition, the traditional evaluation methods are single; only considering the results caused by a single factor cannot reflect the results caused by multiple factors, and supply chain flexibility may be accumulated through internal factors. In view of the above limitations, this paper puts forward the matter-element extension theory, which can completely and comprehensively reflect the different characteristics of the evaluation research object and overcome the disadvantages of the traditional evaluation method which can only select one-sided factors and may lead to the accidental results. At the same time, extension theory can flexibly change the evaluation indicator according to the actual characteristics of the evaluation object, and the application of the model will not be rigid. Using this method to solve the complex problem of the incompatibility of service supply chain flexibility and to make a reasonable distinction between the level of service supply chain flexibility can effectively achieve the compatibility of multiple evaluation indicators.

\section{Construction of the Supply Chain Flexibility Evaluation Indicator System}

According to the connotation of supply chain flexibility, by analyzing the actual operation management of the supply chain and referring to the existing literature research results, this paper expands and extends the flexibility indicator according to the characteristics of dynamic operation of the supply chain. Supply network, operation system, internal and external organizational structure design, and information system are considered as an indispensable part of the supply chain. From the perspective of these parts, the supply chain flexibility is decomposed into ten primary indicators, such as service category and quantity flexibility, human resource flexibility, capital flexibility, logistics flexibility, and partner flexibility, each of which can be decomposed into several secondary indicators.

2.1. Service Category and Quantity Flexibility. Service category and quantity flexibility can measure the range of service category that an organization or enterprise can operate under the condition of profit, which is often related to the variety and quantity of service products that an organization can provide and the cost change brought by such change. There are four secondary indicators under such flexible indicators, including customer order missing rate (mainly involving service product inventory, demand, and shortage), average delayed order rate (mainly involving order urgency, service production capacity, service resource inventory level, and service delivery capacity), average early delivery service rate (reflecting that customers are within the acceptable time range, the ability of the enterprise to submit service first), and average customer waiting rate (mainly related to order quantity, production capacity, and service product delivery path).

2.2. Human Resource Flexibility. Human resource flexibility includes two secondary indicators: skill flexibility and behavior flexibility. Skill flexibility refers to that employees have a wealth of knowledge and skills and that enterprises can provide employees with a large number of learning and training time and opportunities so that employees can obtain the skills needed for multiple posts and different services, so as to flexibly respond to the changes of the working environment and work requirements. It mainly involves the mastery and application of skills, skill training, job rotation, job enrichment and expansion, and the adaptation of skills acquired by employees to the environment. Behavior flexibility refers to the long-term professional training of behavior or service skills, which enables employees to flexibly use a variety of preset and prepared behavior script sets to deal with emergencies in the process 
of work. It mainly involves the behaviors of employees at work, as well as the adaptation of these behaviors to environmental changes and new work contents.

2.3. Capital Flexibility. Capital flexibility includes three secondary indicators: financing capacity flexibility, profitability flexibility, and price flexibility. Among them, the flexibility of financing ability is reflected by the financing cost rate, the flexibility of profitability is reflected by the operating profit rate, and the flexibility of price reflects the adjustable price space that the product can expand when the enterprise realizes the profit.

2.4. Logistics Flexibility. For the supply chain, reducing the cost of transportation, purchasing, and inventory is the key. Logistics flexibility mainly includes three secondary indicators: inventory turnover, diversity of transportation channels available, and distribution accuracy. The high indicator of inventory turnover indicates that the supply chain has a high level of flexibility. Diversity of transportation channels available reflects the ability of the supply chain to quickly select different transportation channels and modes in case of emergency. Distribution accuracy can reflect the ability of zero error distribution of raw materials, semifinished products, spare parts, and other necessary products from the upstream of the supply chain. This indicator is particularly important when the external environment changes.

2.5. Partner Flexibility. The increasingly fierce market competition makes the organic cooperation of all links in the supply chain more important. Partner flexibility is reflected in the ability of enterprises to change and adjust their partners in time when the external environment changes. Partner flexibility includes three secondary indicators: trust mechanisms' build capacity, knowledge sharing rate, and the number of partners that can be selected in time. The more willing and knowledge sharing partners are, the more partners can be adjusted in time and the higher the flexibility level of the supply chain.

2.6. Production Equipment Flexibility. Production equipment flexibility includes three secondary indicators: production equipment trouble-free continuous operation efficiency, maintenance rate of production equipment, and actual productivity of production equipment.

2.7. Technical Flexibility. Technical flexibility is the difficulty of the process of original technology updating and leaping over to new technology, including two secondary indicators of original technology and new technology.

2.8. Time Flexibility. Time flexibility reflects the time needed for the supply chain to respond to customers' needs in time, including two secondary indicators: degree of timely response and delivery flexibility. The higher the degree of timely response, the shorter the response time and the higher the level of supply chain flexibility. Delivery flexibility reflects the ability of the supply chain to respond to changes when delivery time changes.

2.9. Service Supply Flexibility. Service supply flexibility includes two dimensions: hybrid flexibility and new service supply flexibility.

Hybrid flexibility can not only measure the maximum range of different kinds of services that enterprises can produce or provide in a specific time but also measure the response time that service providers need to change the service product mix, including two secondary indicators: hybrid flexibility range and hybrid flexibility time.

New service supply flexibility reflects the degree of difficulty for enterprises to produce or introduce new service products. On the one hand, it considers the time needed for new service products to be introduced into the existing supply system, and on the other hand, it considers the cost needed for the existing service supply system to introduce new service products, including two secondary indicators: new service flexibility time and new service flexibility cost.

2.10. Information Response Flexibility. Information response flexibility of the supply chain is embodied in the ability of members of the supply chain to accept and take action in time to process business information, including three secondary indicators: information response time, information response range, and information distribution accuracy. Information response time is the time taken by each entity in the supply chain to receive and respond to business information. Information response range is the range that the information system can accept and respond to information at the same time. Information distribution accuracy can reflect the ability of the supply chain information system to deal with uncertainty.

According to the above content, the supply chain flexible evaluation indicator system is constructed, which is divided into primary indicators, secondary indicators, secondary indicator description, and indicator nature. The quantitative indicators in secondary indicators are expressed by the calculation formula according to the indicator meaning and data availability. The evaluation standard division of qualitative indicators can be referred to previous studies or yearbook data related to indicators, as shown in Table 1.

\section{Construct the Matter-Element Model of Supply Chain Flexibility Evaluation}

Extension theory was founded by Chinese scholar Cai [22] in the 1980s. It combines matter-element theory with extension set theory, studies matter-element and its changing trend, and studies and solves the changing law of complex problems in a qualitative and quantitative way. The important feature of this theory is that it provides an effective tool to solve the problem of incompatibility. Based on the matterelement model, extension set, and correlation function theory of extension science, the method of multi-indicator 
TABLE 1: Supply chain flexibility evaluation indicator system.

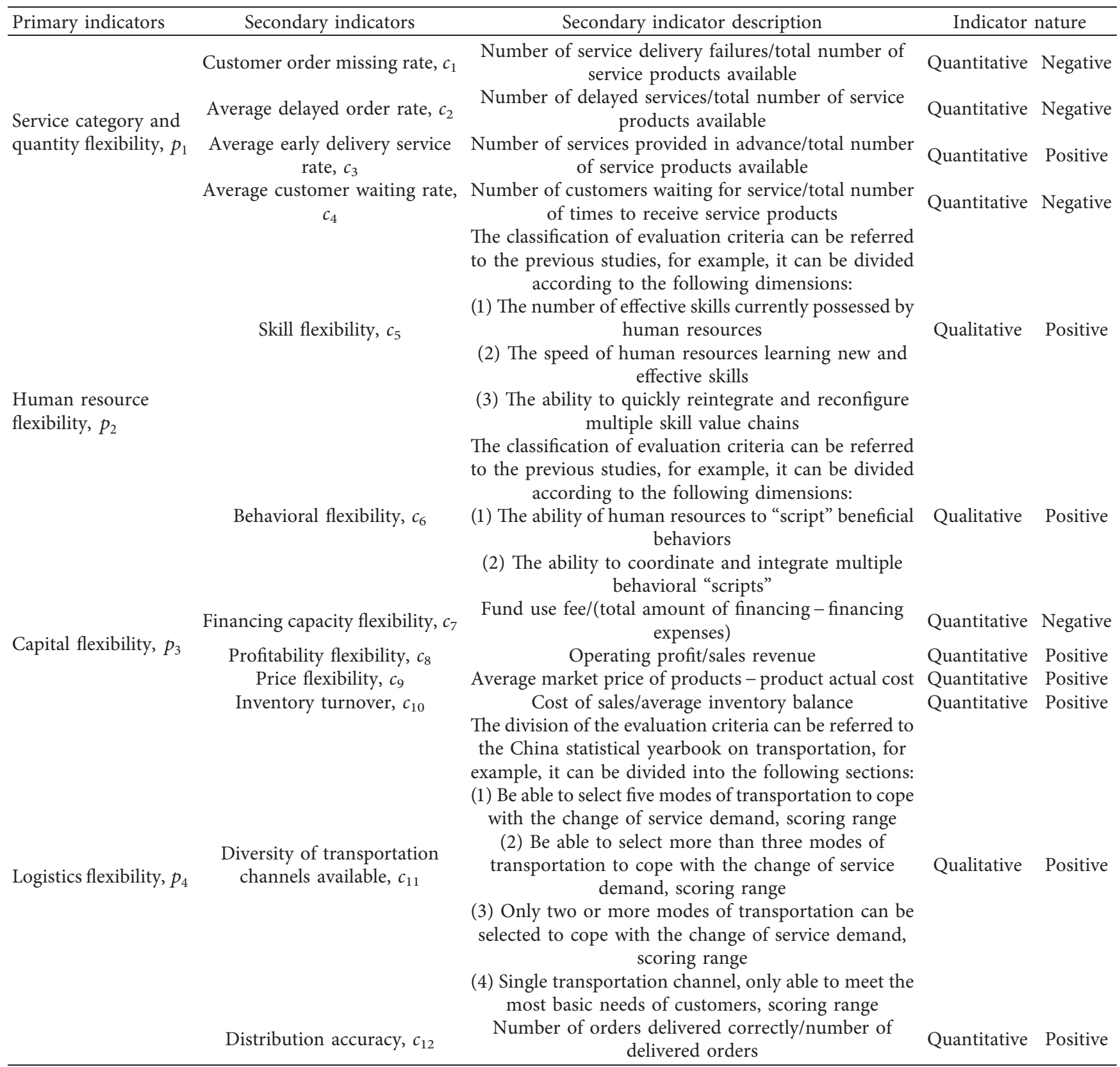


extension comprehensive analysis is a new method of multivariate data quantitative decision-making. In this study, matter-element is used to describe the level and object of supply chain flexibility, extension set, and correlation function which are used to establish the evaluation criteria and the degree of supply chain flexibility, and a multiattribute evaluation model is established to represent the level of supply chain flexibility.

\subsection{Matter-Element Model of Supply Chain Flexibility.} Suppose the supply chain flexibility is $N$, and its quantitative value about feature $C$ is $V$; then, this ternary ordered group is called the fundamental element of things, referred to as matter-element, denoted as $R=(N, C, V) . N, C$, and $V$ are called the three elements of matter-element $R$. If the supply chain flexibility has $n$ characteristics, it is denoted as $c_{1}, c_{2}, c_{3}, \ldots, c_{n}$, and the corresponding characteristic value is denoted as $v_{1}, v_{2}, v_{3}, \ldots, v_{n}$; then, $R$ is denoted as $n$-dimensional matter-element, which can be expressed as the following formula $[22,23]$ :

$$
R=(N, C, V)=\left[\begin{array}{ccc}
N & c_{1} & v_{1} \\
& c_{2} & v_{2} \\
& \vdots & \vdots \\
& c_{n} & v_{n}
\end{array}\right]
$$

\subsection{Evaluation Model of Supply Chain Flexibility}

3.2.1. Classical Domain, Node Domain, and Object to Be Evaluated of Supply Chain Flexibility. Classical domain refers to the value range of each supply chain flexibility evaluation indicator under different levels of supply chain flexibility. There are $m$ supply chain flexibility levels $N_{1}, N_{2}, \ldots, N_{m}$, and the corresponding matter-elements are established as shown in the following formula $[22,23]$ :

$$
R_{j}=\left(N_{j}, c_{i}, v_{i j}\right)=\left[\begin{array}{ccc}
N_{j} & c_{1} & v_{1 j} \\
& c_{2} & v_{2 j} \\
& \vdots & \vdots \\
& c_{n} & v_{n j}
\end{array}\right]=\left[\begin{array}{ccc}
N_{j} & c_{1} & \left\langle a_{1 j}, b_{1 j}\right\rangle \\
& c_{2} & \left\langle a_{2 j}, b_{2 j}\right\rangle \\
\vdots & \vdots \\
& c_{n} & \left\langle a_{n j}, b_{n j}\right\rangle
\end{array}\right],
$$

where $N_{j}$ represent the divided $j(j=1,2, \ldots, m)$ supply chain flexible grades, $c_{i}(i=1,2, \ldots, n)$ represent the $N_{j}$ characteristics of the supply chain flexible grades, $v_{i j}$ represents the quantitative value range of $c_{i}$ specified by $N_{j}$, that is, the numerical range of each supply chain flexible grade with respect to the corresponding characteristics represented by $v_{i j}=\left\langle a_{i j}, b_{i j}\right\rangle, a_{i j}$ and $b_{i j}$ are the upper and lower limits of the classical domain, respectively, and $R_{j}$ is the classical domain of supply chain flexibility.

Its nodal domain $R_{p}$ is constructed by the classical domain, and $R_{p}=R_{j}$, as shown in the following formula $[22,23]$ :

$$
R_{p}=\left(N_{p}, c_{i}, v_{i p}\right)=\left[\begin{array}{ccc}
N_{p} & c_{1} & v_{1 p} \\
& c_{2} & v_{2 p} \\
& \vdots & \vdots \\
& c_{n} & v_{n p}
\end{array}\right]=\left[\begin{array}{ccc}
N_{p} & c_{1} & \left\langle a_{1 p}, b_{1 p}\right\rangle \\
& c_{2} & \left\langle a_{2 p}, b_{2 p}\right\rangle \\
& \vdots & \vdots \\
& c_{n} & \left\langle a_{n p}, b_{n p}\right\rangle
\end{array}\right],
$$

where $N_{p}$ represents the total supply chain flexibility level and $v_{i p}$ is the range of values taken by $N_{p}$ with respect to $c_{i}$ represented by $v_{i p}=\left\langle a_{i p}, b_{i p}\right\rangle, a_{i p}$ and $b_{i p}$ are the upper and lower limits of the node domain, respectively.

For the object to be evaluated, the evaluation indicator information is represented by matter-element, which is called the flexible object of the supply chain to be evaluated, as shown in the following formula $[22,23]$ :

$$
R_{o}=\left(P_{o}, c_{i}, t_{i}\right)=\left[\begin{array}{ccc}
P_{o} & c_{1} & t_{1} \\
& c_{2} & t_{2} \\
& \vdots & \vdots \\
& c_{n} & t_{n}
\end{array}\right],
$$

where $P_{o}$ is the matter-element to be evaluated and $t_{i}$ is the measurement value of $P_{o}$ with respect to $c_{i}$, that is, the actual measurement value of the indicator of the object to be evaluated.

3.2.2. Calculate the Correlation Degree of Supply Chain Flexibility. The correlation degree of each supply chain flexibility level of the object to be evaluated is calculated by the correlation function. The value of the $i(i=1,2, \ldots, n)$-th indicator belongs to the correlation function of the $j(j=1,2, \ldots, m)$-th supply chain flexibility level, as shown in the following formula $[22,23]$ :

$$
K_{j}\left(t_{i}\right)= \begin{cases}\frac{\rho\left(t_{i}, v_{i j}\right)}{\rho\left(t_{i}, v_{i p}\right)-\rho\left(t_{i}, v_{i j}\right)}, & t_{i} \notin v_{i j}, \\ \frac{-\rho\left(t_{i}, v_{i j}\right)}{\left|v_{i j}\right|}, & t_{i} \in v_{i j},\end{cases}
$$

where $K_{j}\left(t_{i}\right)$ is the correlation degree of each supply chain flexibility indicator with respect to each evaluation level, $\rho\left(t_{i}, v_{i j}\right)$ is the distance between $t_{i}$ and $v_{i j}=\left\langle a_{i j}, b_{i j}\right\rangle$ in a finite interval, and $\rho\left(t_{i}, v_{i p}\right)$ is the distance between $t_{i}$ and $v_{i p}=\left\langle a_{i p}, b_{i p}\right\rangle$ in a finite interval, and the distance calculation formulae are shown in formulae (6) and (7) $[22,23]$ :

$$
\begin{gathered}
\rho\left(t_{i}, v_{i j}\right)=\left|t_{i}-\frac{1}{2}\left(a_{i j}+b_{i j}\right)\right|-\frac{1}{2}\left(b_{i j}-a_{i j}\right), \\
\rho\left(t_{i}, v_{i p}\right)=\left|t_{i}-\frac{1}{2}\left(a_{i p}+b_{i p}\right)\right|-\frac{1}{2}\left(b_{i p}-a_{i p}\right) .
\end{gathered}
$$

3.2.3. Calculate the Weight of the Evaluation Indicator. The supply chain flexibility is regarded as a system, and each evaluation indicator is a subsystem. The value of each 
evaluation object under the indicator can be regarded as the possible result of the subsystem, and the entropy weight of the indicator can be calculated according to its probability. According to the definition of entropy, the entropy of $m$ evaluation objects and $n$ indicators is calculated as shown in the following formula [24]:

$$
E_{i}=-\frac{\sum_{j=1}^{m} T_{i j} \ln T_{i j}}{\ln m}, \quad i=1,2, \ldots, n ; j=1,2, \ldots, m,
$$

where $T_{i j}=\left(t_{i j} / \sum_{j=1}^{m} t_{i j}\right)\left(T_{i j} \neq 0\right) \quad$ and $T_{i j}=\left(\left(1+t_{i j}\right) /\right.$ $\left.\sum_{j=1}^{m}\left(1+t_{i j}\right)\right)\left(T_{i j}=0\right), t_{i j}$ is the value of the $i$-th indicator of the $j$-th evaluation object. The calculation formulae of entropy weight $\lambda_{i}$ and weight $W$ of evaluation indicators are shown in formulae (9) and (10) [24]:

$$
\begin{aligned}
& \lambda_{i}=\frac{1-E_{i}}{\sum_{i=1}^{n}\left(1-E_{i}\right)}, \\
& W=\left(\lambda_{i}\right)_{1 \times n^{n}}
\end{aligned}
$$

3.2.4. Calculation of Comprehensive Correlation Degree and Evaluation of Grade. The correlation degree between each evaluation indicator and the grade standard is weighted and summed to get the comprehensive correlation degree, as shown in the following formula $[22,23]$ :

$$
K_{j}\left(R_{o}\right)=\sum_{i=1}^{n} \lambda_{i} K_{j}\left(t_{i}\right)
$$

If $K_{j}\left(R_{o}\right)=\max \left\{K_{j}\left(R_{o}\right)\right\}(j=1,2, \ldots, m)$, then the supply chain flexibility grade is $j$.

\section{Example Analysis}

In recent years, the automobile service industry has been developing rapidly in China, and its supply chain flexibility is representative. In this paper, four automobile service companies (A, B, C, and D) in N city of China are selected as research objects to evaluate and analyze their supply chain flexibility.

4.1. Supply Chain Flexibility Classification. In order to better reflect the level of supply chain flexibility, it is necessary to classify the level of supply chain flexibility of the automobile service industry. The supply chain flexibility level is divided into four levels according to industry reports over the years such as China's automobile service industry market status survey and development prospect analysis report (2019-2025) and China's automobile service industry development status survey and development trend analysis report (2018-2024). The level of supply chain flexibility from superior to inferior corresponds to I (excellent), II (good), III (medium), and IV (poor), and the meaning of each level of supply chain flexibility is shown in Table 2. By using the concept of the extension set, the gradual classification relationship of $\{$ excellent $\longrightarrow$ good $\longrightarrow$ medium $\longrightarrow$ poor $\}$ is extended from qualitative description to quantitative description, so as to identify the hierarchical relationship of this concept. The evaluation of supply chain flexibility is expressed as $P=\{$ excellent $\longrightarrow$ good $\longrightarrow$ medium $\longrightarrow$ poor $\}, \quad I=\{$ excellent $\}, \quad I I=\{$ good $\}, \quad I I I=\{$ medium $\}, \quad$ and IV $=\{$ poor $\}, I, I I, I I I, I V \in P$. For any $p \in P$, it is judged that it belongs to I, II, III, or IV.

4.2. Determination of Classical Domain, Nodal Domain, and Weight. To autoservice industry based on the above cognizance of flexible supply chain hierarchies, combined with years of China's autoservice industry market research report, in reference to the China $\mathrm{N}$ city area actual situation on the basis of the background value and expert advice, determine range of supply chain flexible evaluation of each indicator hierarchy standard, the resulting classical domain and joint domain value interval values, and by formulae $(8) \sim(10)$ to determine evaluation indicator weights, and the results are shown in Table 3.

4.3. Determination of Matter-Element to Be Evaluated. To evaluate the supply chain flexibility level of four automobile service companies (company A, company B, company C, and company D) in $\mathrm{N}$ city, China, it is necessary to determine the actual value of each company's supply chain flexibility to be evaluated, that is, $t_{i}$ in formula (4). The evaluation indicator system constructed in this paper has 29 secondary indicators, including 23 quantitative indicators and 6 qualitative indicators. The acquisition of quantitative indicator data is mainly through the collection of the original data of each company, including the company's operation report, financial report, annual report, and field research data. The qualitative indicator data were obtained mainly by means of self-filled questionnaire and structured interview, and a seven-level Likert scale was designed for experts and staff to evaluate and score the indicator and quantify the qualitative indicator. After the positive indicator is quantified, the higher the score is, the higher the flexibility level of the indicator is. According to this, the supply chain flexible matter-element models of four automobile service companies are constructed.

4.4. Calculation of Correlation Degree and Determination of Evaluation Grade. According to the volume value $t_{i}$ of each evaluation indicator $c_{i}$ of the automobile service company and formulae (5) (7), the correlation degree $K_{j}\left(t_{i}\right)$ of each company's supply chain flexibility evaluation secondary indicator with respect to the evaluation grade can be obtained, respectively. By judging the degree that the actual volume value $t_{i}$ in the object to be evaluated $R_{o}$ tends to the adjacent grade $N_{j}$, it can reflect a trend of the level change of the object to be evaluated. If $K_{j}\left(t_{i}\right)<-1$, it means that the supply chain flexibility does not belong to grade $j$ and does not have the conditions to meet the grade standard; the smaller the value is, the larger the gap is; if $-1 \leq K_{j}\left(t_{i}\right) \leq 0$, it means that the supply chain flexibility does not belong to grade $j$ but has the conditions to convert to the grade; the larger the value is, the easier to convert; and if $K_{j}\left(t_{i}\right)>0$, it means that the supply chain flexibility meets the 
TABLE 2: Classification of supply chain flexibility in the automobile service industry.

\begin{tabular}{l}
\hline Grade \\
(1) The specialty of the supply chain, the adaptability, and flexibility of service are strong \\
I (excellent) \\
(2) On the basis of specialization, it tends to be more personalized \\
a high level of flexibility \\
(1) The specialty of the supply chain, the adaptability, and flexibility of service are stronger \\
(2) On the basis of specialization, it can be more personalized \\
(3) The ability to effectively respond to the change of demand is stronger, the response ability of service supply chain is \\
stronger, and the level of flexibility is higher \\
(1) The specialty of the supply chain, the adaptability, and flexibility of service are general \\
(2) The flow efficiency of information exchange among the main parts of the supply chain is general. \\
(3) The ability to effectively respond to changes in demand is general, the response ability of the supply chain is general, and \\
the level of flexibility is general \\
(1) The specialty of the supply chain, the adaptability, and flexibility of service are weak \\
(2) The flow efficiency of information exchange among the main parts of the supply chain is low \\
(medium) The ability to deal with the change of demand effectively is weak, the response ability of the supply chain is weak, and the \\
IV (poor) level of flexibility is low
\end{tabular}

TABLE 3: Classic domain, node domain, and weight of supply chain flexibility evaluation indicators of the automobile service industry.

\begin{tabular}{|c|c|c|c|c|c|c|}
\hline \multirow{2}{*}{ Indicators } & \multicolumn{4}{|c|}{ Classical domain value interval } & \multirow{2}{*}{ Node domain value interval } & \multirow{2}{*}{ Weight } \\
\hline & I (excellent) & II (good) & III (medium) & IV (poor) & & \\
\hline$c_{1}$ & {$[0,0.056)$} & {$[0.056,0.166)$} & {$[0.166,0.222)$} & {$[0.222,0.333]$} & {$[0,0.333]$} & 0.0886 \\
\hline$c_{2}$ & {$[0.053,0.156)$} & {$[0.156,0.215)$} & {$[0.215,0.315)$} & {$[0.315,0.421]$} & {$[0.053,0.421]$} & 0.0151 \\
\hline$c_{3}$ & {$[0.85,0.94]$} & {$[0.75,0.85)$} & {$[0.65,0.75)$} & {$[0.55,0.65)$} & {$[0.55,0.94]$} & 0.0079 \\
\hline$c_{4}$ & {$[0,0.166)$} & {$[0.166,0.253)$} & {$[0.253,0.368)$} & {$[0.368,0.588]$} & {$[0,0.588]$} & 0.0065 \\
\hline$c_{5}$ & {$[6,7]$} & {$[4,6)$} & {$[2,4)$} & {$[1,2)$} & {$[6,7]$} & 0.0014 \\
\hline$c_{6}$ & {$[6,7]$} & {$[5,6)$} & {$[3,5)$} & {$[1,3)$} & {$[6,7]$} & 0.0003 \\
\hline$c_{7}$ & {$[0.1,0.3)$} & {$[0.3,0.4)$} & {$[0.4,0.5)$} & {$[0.5,0.7]$} & {$[0.1,0.7]$} & 0.0882 \\
\hline$c_{8}$ & {$[0.17,0.25]$} & {$[0.15,0.17)$} & {$[0.04,0.15)$} & {$[0.01,0.04)$} & {$[0.01,0.25]$} & 0.0383 \\
\hline$c_{9}$ & {$[279,360]$} & {$[200,279)$} & {$[119,200)$} & {$[87,119)$} & {$[87,360]$} & 0.0805 \\
\hline$c_{10}$ & {$[5.54,7.29]$} & {$[3.13,5.54)$} & {$[0.95,3.13)$} & {$[0.65,0.95)$} & {$[0.65,7.29]$} & 0.1416 \\
\hline$c_{11}$ & {$[6,7]$} & {$[4,6)$} & {$[2,4)$} & {$[1,2)$} & {$[1,7]$} & 0.1280 \\
\hline$c_{12}$ & {$[0.94,1]$} & {$[0.79,0.94)$} & {$[0.62,0.79)$} & {$[0.38,0.62)$} & {$[0.38,1]$} & 0.0124 \\
\hline$c_{13}$ & {$[6,7]$} & {$[4,6)$} & {$[2,4)$} & {$[1,2)$} & {$[1,7]$} & 0.1282 \\
\hline$c_{14}$ & {$[0.82,0.94]$} & {$[0.64,0.82)$} & {$[0.49,0.64)$} & {$[0.23,0.49)$} & {$[0.23,0.94]$} & 0.0476 \\
\hline$c_{15}$ & {$[17,20]$} & {$[14,17)$} & {$[9,14)$} & {$[5,9)$} & {$[5,20]$} & 0.0656 \\
\hline$c_{16}$ & {$[0.71,0.98]$} & {$[0.63,0.71)$} & {$[0.51,0.63)$} & {$[0.32,0.51)$} & {$[0.32,0.98]$} & 0.0033 \\
\hline$c_{17}$ & {$[0.11,0.23)$} & {$[0.23,0.41)$} & {$[0.41,0.57)$} & {$[0.57,0.72]$} & {$[0.11,0.72]$} & 0.0107 \\
\hline$c_{18}$ & {$[0.9,1]$} & {$[0.8,0.9)$} & {$[0.7,0.8)$} & {$[0.6,0.7)$} & {$[0.6,1]$} & 0.0013 \\
\hline$c_{19}$ & {$[6,7]$} & {$[5,6)$} & {$[4,5)$} & {$[3,4)$} & {$[3,7]$} & 0.0142 \\
\hline$c_{20}$ & {$[6,7]$} & {$[5,6)$} & {$[4,5)$} & {$[3,4)$} & {$[3,7]$} & 0.0019 \\
\hline$c_{21}$ & {$[0.37,0.48)$} & {$[0.48,0.51)$} & {$[0.51,0.65)$} & {$[0.65,0.98]$} & {$[0.37,0.98]$} & 0.0077 \\
\hline$c_{22}$ & {$[0.76,0.85]$} & {$[0.59,0.76)$} & {$[0.29,0.59)$} & {$[0.09,0.29)$} & {$[0.09,0.85]$} & 0.0429 \\
\hline$c_{23}$ & {$[20,30]$} & {$[15,20)$} & {$[11,15)$} & {$[5,11)$} & {$[5,30]$} & 0.0078 \\
\hline$c_{24}$ & {$[1,2)$} & {$[2,3)$} & {$[3,6)$} & {$[6,7]$} & {$[1,7]$} & 0.0025 \\
\hline$c_{25}$ & {$[1,2)$} & {$[2,3)$} & {$[3,4)$} & {$[4,5]$} & {$[1,5]$} & 0.0197 \\
\hline$c_{26}$ & {$[7,9)$} & {$[9,13)$} & {$[13,17)$} & {$[17,24]$} & {$[7,24]$} & 0.0181 \\
\hline$c_{27}$ & {$[3,5)$} & {$[5,7)$} & {$[7,9)$} & {$[9,14]$} & {$[3,14]$} & 0.0073 \\
\hline$c_{28}$ & {$[0.8,0.9]$} & {$[0.7,0.8)$} & {$[0.5,0.7)$} & {$[0.3,0.5)$} & {$[0.3,0.9]$} & 0.0071 \\
\hline$c_{29}$ & {$[0.84,0.92]$} & {$[0.77,0.84)$} & {$[0.6,0.77)$} & {$[0.42,0.6)$} & {$[0.42,0.92]$} & 0.0052 \\
\hline
\end{tabular}

requirements of grade $j$, the higher the value is. Tables 4 and 5 show the secondary indicator correlation and evaluation grade of supply chain flexibility evaluation of four automobile service companies.

By substituting the weight of each indicator in Table 3 and the correlation degree $K_{j}\left(t_{i}\right)$ of each secondary indicator in Table 4 into formula (11), the correlation degree and comprehensive correlation degree of the primary indicators of supply chain flexibility evaluation from company A to company D can be obtained, respectively, so as to evaluate the correlation degree of each company's primary indicators of supply chain flexibility and the level of each company's supply chain flexibility. The calculation results are shown in Tables 6-8. 
TABLE 4: Secondary indicator correlation degree and grade of supply chain flexibility evaluation of companies A and B.

\begin{tabular}{|c|c|c|c|c|c|c|c|c|c|c|}
\hline \multirow{2}{*}{ Indicators } & \multicolumn{4}{|c|}{ Company A } & \multirow{2}{*}{ Grade } & \multicolumn{4}{|c|}{ Company B } & \multirow{2}{*}{ Grade } \\
\hline & I & II & III & IV & & I & II & III & IV & \\
\hline$c_{1}$ & 0.0607 & -0.0607 & -0.6831 & -0.7631 & Excellent & -0.3187 & 0.4473 & -0.3663 & -0.5261 & Good \\
\hline$c_{2}$ & -0.2571 & 0.0763 & -0.0278 & -0.3989 & Good & -0.0169 & 0.0305 & -0.3531 & -0.6000 & Good \\
\hline$c_{3}$ & -0.7283 & -0.5925 & -0.1850 & 0.1850 & Poor & -0.2869 & 0.3940 & -0.2074 & -0.4807 & Good \\
\hline$c_{4}$ & -0.3964 & -0.2397 & 0.3017 & -0.1199 & Medium & -0.5822 & -0.4737 & -0.1986 & 0.1986 & Poor \\
\hline$c_{5}$ & -0.3503 & 0.4150 & -0.2767 & -0.5660 & Good & -0.3848 & 0.1650 & -0.1100 & -0.4660 & Good \\
\hline$c_{6}$ & -0.3322 & 0.0100 & -0.0050 & -0.5025 & Good & -0.3408 & -0.0327 & 0.0350 & -0.4825 & Medium \\
\hline$c_{7}$ & 0.0105 & -0.0105 & -0.3403 & -0.5053 & Excellent & 0.3290 & -0.3290 & -0.5527 & -0.6645 & Excellent \\
\hline$c_{8}$ & -0.4825 & -0.4086 & 0.4800 & -0.3894 & Medium & -0.2475 & -0.1387 & 0.1745 & -0.4324 & Medium \\
\hline$c_{9}$ & -0.8177 & -0.6903 & 0.0370 & -0.0789 & Medium & -0.1955 & 0.3291 & -0.3313 & -0.5560 & Good \\
\hline$c_{10}$ & -0.9425 & -0.8867 & -0.0630 & 0.0630 & Poor & -0.3044 & 0.4350 & -0.2520 & -0.5092 & Good \\
\hline$c_{11}$ & -0.8600 & -0.7667 & -0.3000 & 0.3000 & Poor & -0.3077 & 0.4000 & -0.4000 & -0.6400 & Good \\
\hline$c_{12}$ & -0.6802 & -0.5632 & -0.2538 & 0.2538 & Poor & -0.4005 & 0.1953 & -0.1395 & -0.5245 & Good \\
\hline$c_{13}$ & -0.8235 & -0.7059 & -0.1176 & 0.1176 & Poor & -0.2730 & 0.3006 & -0.4663 & -0.6798 & Good \\
\hline$c_{14}$ & -0.7429 & -0.6300 & -0.4165 & 0.4165 & Poor & -0.1618 & 0.1594 & -0.5043 & -0.6696 & Good \\
\hline$c_{15}$ & -0.9167 & -0.8889 & -0.7500 & 0.2500 & Poor & -0.2857 & 0.3333 & -0.1667 & -0.5455 & Good \\
\hline$c_{16}$ & 0.2267 & -0.2267 & -0.4034 & -0.5557 & Excellent & 0.3411 & -0.3411 & -0.4917 & -0.6215 & Excellent \\
\hline$c_{17}$ & -0.4286 & -0.0968 & 0.1875 & -0.3171 & Medium & -0.5714 & -0.3226 & 0.3750 & -0.2222 & Medium \\
\hline$c_{18}$ & -0.1984 & 0.3290 & -0.3355 & -0.5570 & Good & 0.0890 & -0.0890 & -0.5445 & -0.6963 & Excellent \\
\hline$c_{19}$ & -0.3214 & 0.1000 & -0.0500 & -0.3667 & Good & -0.5667 & -0.3500 & 0.3000 & -0.1875 & Medium \\
\hline$c_{20}$ & -0.2500 & 0.5000 & -0.2500 & -0.5000 & Good & 0.0400 & -0.0400 & -0.5200 & -0.6800 & Excellent \\
\hline$c_{21}$ & -0.8732 & -0.8651 & -0.8079 & 0.1921 & Poor & -0.5534 & -0.5249 & -0.3233 & 0.3233 & Poor \\
\hline$c_{22}$ & -0.9651 & -0.9532 & -0.8830 & 0.1170 & Poor & -0.8245 & -0.7648 & -0.4120 & 0.4120 & Poor \\
\hline$c_{23}$ & -0.0833 & 0.2000 & -0.2667 & -0.4211 & Good & -0.2000 & 0.4000 & -0.1429 & -0.3333 & Good \\
\hline$c_{24}$ & -0.8400 & -0.8000 & -0.2000 & 0.2000 & Poor & -0.8800 & -0.8500 & -0.4000 & 0.4000 & Poor \\
\hline$c_{25}$ & -0.4333 & -0.1500 & 0.3000 & -0.2917 & Medium & -0.5000 & -0.2500 & 0.5000 & -0.2500 & Medium \\
\hline$c_{26}$ & -0.4167 & -0.1250 & 0.2500 & -0.3000 & Medium & -0.3333 & 0.5000 & -0.3333 & -0.6000 & Good \\
\hline$c_{27}$ & -0.3750 & -0.1667 & 0.5000 & -0.1667 & Medium & -0.5556 & -0.4286 & -0.2000 & 0.2000 & Poor \\
\hline$c_{28}$ & -0.5118 & -0.3898 & 0.2205 & -0.1530 & Medium & -0.3514 & -0.0770 & 0.0910 & -0.4545 & Medium \\
\hline$c_{29}$ & -0.7381 & -0.6857 & -0.3889 & 0.3889 & Poor & -0.6667 & -0.6000 & -0.2222 & 0.2222 & Poor \\
\hline
\end{tabular}

4.5. Data Analysis. It can be seen from Table 8 that the comprehensive evaluation grade of company $\mathrm{A}$ is transformation to poor, company $\mathrm{B}$ is good, company $\mathrm{C}$ is medium, and company $\mathrm{D}$ is transformation to poor. It can be seen that company $\mathrm{B}$ has the highest rating among the four companies, which reflects its professional supply chain, strong ability to effectively respond to demand changes, and high flexibility. Company A and company D have weak adaptability, weak response ability, and low flexibility in the supply chain. The supply chain of company $\mathrm{C}$ is generally flexible.

The data in Tables 6 and 7 are used to analyze the results in Table 8, that is, the supply chain flexibility level of each company is analyzed one by one. Among the primary indicators of company $\mathrm{B}$, there are one excellent, five good, two medium, one poor, one transformation to poor, $80 \%$ of which are above medium, and $60 \%$ of which are above good. Therefore, the indicators to be concerned are $p_{6}$ production equipment flexibility and $p_{7}$ technology flexibility, and the key indicators are $p_{8}$ time flexibility and $p_{10}$ information response flexibility. In the same way, company $\mathrm{C}$ accounts for $70 \%$ of the indicators above the medium level (including transformation to medium), while company $\mathrm{C}$ accounts for only $20 \%$ of the indicators above the good level. This shows that the supply chain flexibility of the company is in general in most aspects, and there is a huge room for improvement.
Company A and company D account for $60 \%$ of the indicators above the medium level (including transformation to medium). The difference is that company $\mathrm{D}$ accounts for $40 \%$ of the indicators above the good level (including transformation to good). It also shows that the performance of $p_{3}$ capital flexibility, $p_{5}$ partner flexibility, $p_{6}$ production equipment flexibility, and $p_{8}$ time flexibility, which is currently poor, is the focus of future work improvement of the company. Through the overall analysis of the primary indicators, we can see that the four companies' indicator $p_{2}$ human resource flexibility has reached a good level, and the performance of indicator $p_{9}$ service supply flexibility is also good, reaching above the medium level, but $p_{8}$ time flexibility of the four companies is in a poor grade.

By analyzing the data in Table 4 , we can get the secondary indicators that affect the supply chain flexibility level of each company. Taking company D as an example, because $p_{3}$ capital flexibility, $p_{5}$ partner flexibility, $p_{6}$ production equipment flexibility, and $p_{8}$ time flexibility are the four primary indicators that need to be focused on, combined with the secondary indicator correlation in Table 4 , it is found that the secondary indicators $c_{7}$ under $p_{3}, c_{13}, c_{15}$ and $c_{15}$ under $p_{5}, c_{17}$, under $p_{6}, c_{21}$, and $c_{22}$ under $p_{8}$ are all in poor grades. Based on the further analysis of the investigation of company $\mathrm{D}, c_{7}$ financing capacity flexibility is poor mainly because the development of the 
TABle 5: Secondary indicator correlation degree and grade of supply chain flexibility evaluation of companies C and D.

\begin{tabular}{|c|c|c|c|c|c|c|c|c|c|c|}
\hline \multirow{2}{*}{ Indicators } & \multicolumn{4}{|c|}{ Company C } & \multirow{2}{*}{ Grade } & \multicolumn{4}{|c|}{ Company D } & \multirow{2}{*}{ Grade } \\
\hline & $\mathrm{I}$ & II & III & IV & & I & II & III & IV & \\
\hline$c_{1}$ & -0.3993 & -0.0036 & 0.0107 & -0.2498 & Medium & -0.3852 & 0.1455 & -0.0964 & -0.3243 & Good \\
\hline$c_{2}$ & -0.2812 & -0.0408 & 0.0720 & -0.3542 & Medium & -0.3547 & -0.1699 & 0.3500 & -0.2754 & Medium \\
\hline$c_{3}$ & 0.3078 & -0.3078 & -0.6721 & -0.7852 & Excellent & -0.2632 & 0.5000 & -0.2632 & -0.5172 & Good \\
\hline$c_{4}$ & -0.4953 & -0.3642 & -0.0318 & 0.0318 & Poor & -0.6597 & -0.5713 & -0.3473 & 0.3473 & Poor \\
\hline$c_{5}$ & -0.3634 & 0.3350 & -0.2233 & -0.5340 & Good & -0.3387 & 0.4750 & -0.3167 & -0.5900 & Good \\
\hline$c_{6}$ & -0.3512 & -0.0763 & 0.0900 & -0.4550 & Medium & -0.3175 & 0.1300 & -0.0650 & -0.5325 & Good \\
\hline$c_{7}$ & -0.2953 & -0.0603 & 0.1810 & -0.2251 & Medium & -0.8855 & -0.8473 & -0.7710 & 0.2290 & Poor \\
\hline$c_{8}$ & 0.2950 & -0.2950 & -0.4360 & -0.7314 & Excellent & -0.1633 & 0.0300 & -0.0060 & -0.5267 & Good \\
\hline$c_{9}$ & -0.4375 & -0.0442 & 0.0617 & -0.4130 & Medium & -0.9583 & -0.9292 & -0.7500 & 0.2500 & Poor \\
\hline$c_{10}$ & -0.6596 & -0.3289 & 0.3741 & -0.4505 & Medium & -0.3203 & 0.3528 & -0.2044 & -0.4780 & Good \\
\hline$c_{11}$ & -0.6500 & -0.4167 & 0.3750 & -0.3000 & Medium & 0.2400 & -0.2400 & -0.7467 & -0.8480 & Excellent \\
\hline$c_{12}$ & -0.4460 & -0.2410 & 0.4253 & -0.1903 & Medium & -0.4112 & 0.0740 & -0.0529 & -0.4766 & Good \\
\hline$c_{13}$ & -0.3799 & 0.2095 & -0.1396 & -0.4838 & Good & -0.8414 & -0.7356 & -0.2069 & 0.2069 & Poor \\
\hline$c_{14}$ & -0.4725 & -0.2410 & 0.3413 & -0.1413 & Medium & -0.6585 & -0.5085 & -0.2250 & 0.2250 & Poor \\
\hline$c_{15}$ & -0.5833 & -0.4444 & 0.2000 & -0.1667 & Medium & -0.7500 & -0.6667 & -0.2500 & 0.2500 & Poor \\
\hline$c_{16}$ & -0.1425 & 0.3275 & -0.0749 & -0.3111 & Good & 0.2456 & -0.2456 & -0.4180 & -0.5666 & Excellent \\
\hline$c_{17}$ & -0.7347 & -0.5806 & -0.1333 & 0.1333 & Poor & -0.8163 & -0.7097 & -0.4000 & 2.0000 & Poor \\
\hline$c_{18}$ & -0.3286 & 0.0410 & -0.0205 & -0.3470 & Good & -0.2961 & 0.2740 & -0.1370 & -0.4247 & Good \\
\hline$c_{19}$ & -0.9000 & -0.8500 & -0.7000 & 0.3000 & Poor & -0.4333 & -0.1500 & 0.3000 & -0.2917 & Medium \\
\hline$c_{20}$ & 0.4000 & -0.4000 & -0.7000 & -0.8000 & Excellent & -0.1875 & 0.3000 & -0.3500 & -0.5667 & Good \\
\hline$c_{21}$ & -0.5066 & -0.4751 & -0.2524 & 0.2524 & Poor & -0.3892 & -0.3500 & -0.0713 & 0.0706 & Poor \\
\hline$c_{22}$ & -0.7546 & -0.6712 & -0.1780 & 0.1780 & Poor & -0.8361 & -0.7804 & -0.4510 & 0.4510 & Poor \\
\hline$c_{23}$ & -0.1429 & 0.4000 & -0.2000 & -0.3684 & Good & 0.3000 & -0.3000 & -0.5333 & -0.6316 & Excellent \\
\hline$c_{24}$ & -0.6800 & -0.6000 & 0.2000 & -0.2727 & Medium & -0.8600 & -0.8250 & -0.3000 & 0.3000 & Poor \\
\hline$c_{25}$ & -0.2222 & 0.4000 & -0.3000 & -0.5333 & Good & -0.1875 & 0.3000 & -0.3500 & -0.5667 & Good \\
\hline$c_{26}$ & -0.4667 & -0.2727 & 0.2500 & -0.1111 & Medium & -0.6000 & -0.4545 & -0.1429 & 0.1429 & Poor \\
\hline$c_{27}$ & -0.5222 & -0.3857 & -0.1400 & 0.1400 & Poor & -0.6667 & -0.5714 & -0.4000 & 0.4000 & Poor \\
\hline$c_{28}$ & -0.3236 & 0.0830 & -0.0415 & -0.5208 & Good & -0.2922 & 0.2970 & -0.1485 & -0.5743 & Good \\
\hline$c_{29}$ & -0.5476 & -0.4571 & 0.0588 & -0.0500 & Medium & -0.4000 & -0.2727 & 0.4706 & -0.2500 & Medium \\
\hline
\end{tabular}

TABle 6: Primary indicators' correlation degree and grade of supply chain flexibility evaluation of companies A and B.

\begin{tabular}{|c|c|c|c|c|c|c|c|c|c|c|}
\hline \multirow{2}{*}{ Indicators } & \multicolumn{4}{|c|}{ Company A } & \multirow{2}{*}{ Grade } & \multicolumn{4}{|c|}{ Company B } & \multirow{2}{*}{ Grade } \\
\hline & I & II & III & IV & & I & II & III & IV & \\
\hline$p_{1}$ & -0.0580 & -0.0886 & -0.5115 & -0.6175 & Transformation to poor & -0.2924 & 0.3395 & -0.3447 & -0.4926 & Good \\
\hline$p_{2}$ & -0.4052 & 0.2566 & -0.7414 & -1.1726 & Good & -0.6696 & 0.4704 & -0.4297 & -0.9614 & Good \\
\hline$p_{3}$ & -0.4027 & -0.3484 & -0.0419 & -0.3181 & $\begin{array}{l}\text { Transformation to } \\
\text { medium }\end{array}$ & 0.0185 & -0.0379 & -0.3321 & -0.5794 & Excellent \\
\hline$p_{4}$ & -0.8935 & -0.8179 & -0.1790 & 0.1790 & Poor & -0.3101 & 0.4085 & -0.3142 & -0.5692 & Good \\
\hline$p_{5}$ & -0.8329 & -0.7406 & -0.3484 & 0.2125 & Poor & -0.2545 & 0.2817 & -0.3924 & -0.6413 & Good \\
\hline$p_{6}$ & -0.2670 & -0.0898 & 0.0158 & -0.3888 & Medium & -0.3184 & -0.3073 & 0.1105 & -0.3482 & Medium \\
\hline$p_{7}$ & -0.3129 & 0.1480 & -0.0740 & -0.3827 & Good & -0.4939 & -0.3128 & 0.2017 & -0.2465 & Medium \\
\hline$p_{8}$ & -0.9511 & -0.9398 & -0.8716 & 0.1284 & Poor & -0.7833 & -0.7284 & -0.3985 & 0.3985 & Poor \\
\hline$p_{9}$ & -0.3913 & -0.1175 & 0.1630 & -0.2902 & Medium & -0.4083 & 0.1066 & 0.0351 & -0.3614 & Good \\
\hline$p_{10}$ & -0.5205 & -0.3847 & 0.1637 & -0.0146 & Medium & -0.5113 & -0.3471 & -0.1009 & -0.0303 & $\begin{array}{l}\text { Transformation to } \\
\text { poor }\end{array}$ \\
\hline
\end{tabular}

company is in the transition stage from introducing innovation to independent innovation, the innovation work in all aspects is not mature enough, and the cost of capital invested at the current stage is high, resulting in high capital use fee, thus improving the financing cost rate. $c_{13}$ trust mechanism build ability, $c_{14}$ knowledge sharing rate, and $c_{15}$ number of partners that can be selected in time are rated as poor grades mainly due to the limited efficiency of information transfer between suppliers and all parties, the weak ability to enhance their own competitive strength with the help of partners, the poor communication and cooperation between the main parts of the supply chain, and the low efficiency of information transfer, resulting in low supply flexibility level of the chain. The main reason for the poor $c_{17}$ maintenance rate of production equipment is that the training of professional skills of the company's employees is not in place, and the employees are not proficient in the use of equipment. The poor grade of $c_{21}$ 
TABLe 7: Primary indicators' correlation degree and grade of supply chain flexibility evaluation of companies C and D.

\begin{tabular}{|c|c|c|c|c|c|c|c|c|c|c|}
\hline \multirow{2}{*}{ Indicators } & \multicolumn{4}{|c|}{ Company C } & \multirow{2}{*}{ Grade } & \multicolumn{4}{|c|}{ Company D } & \multirow{2}{*}{ Grade } \\
\hline & I & II & III & IV & & I & II & III & IV & \\
\hline$p_{1}$ & -0.3422 & -0.0486 & -0.0294 & -0.2834 & $\begin{array}{l}\text { Transformation to } \\
\text { medium }\end{array}$ & -0.3883 & 0.0892 & -0.0642 & -0.2939 & Good \\
\hline$p_{2}$ & -0.7034 & 0.2155 & -0.1988 & -0.8038 & Good & -0.7234 & 0.5048 & -0.3375 & -0.8740 & Good \\
\hline$p_{3}$ & -0.2414 & -0.0975 & 0.0206 & -0.3918 & Medium & -0.7803 & -0.7170 & -0.6214 & 0.0975 & Poor \\
\hline$p_{4}$ & -0.6458 & -0.3648 & 0.3768 & -0.3707 & Medium & -0.0701 & 0.0715 & -0.4438 & -0.6458 & Good \\
\hline$p_{5}$ & -0.4534 & -0.0570 & 0.0475 & -0.3301 & Medium & -0.7805 & -0.6721 & -0.2222 & 0.2222 & Poor \\
\hline$p_{6}$ & -0.5723 & -0.3318 & -0.1113 & -0.0030 & $\begin{array}{l}\text { Transformation to } \\
\text { poor }\end{array}$ & -0.5424 & -0.5274 & -0.3822 & 1.2414 & Poor \\
\hline$p_{7}$ & -0.7441 & -0.7960 & -0.7000 & 0.1681 & Poor & -0.4039 & -0.0960 & 0.2221 & -0.3246 & Medium \\
\hline$p_{8}$ & -0.7170 & -0.6414 & -0.1893 & 0.1893 & Poor & -0.7683 & -0.7151 & -0.3934 & 0.3932 & Poor \\
\hline$p_{9}$ & -0.3251 & 0.0949 & -0.0508 & -0.3341 & Good & -0.2984 & -0.1400 & -0.2993 & -0.2652 & $\begin{array}{c}\text { Transformation to } \\
\text { good }\end{array}$ \\
\hline$p_{10}$ & -0.4572 & -0.2355 & -0.0518 & -0.1488 & $\begin{array}{l}\text { Transformation to } \\
\text { medium }\end{array}$ & -0.4609 & -0.1789 & -0.0787 & -0.1238 & $\begin{array}{c}\text { Transformation to } \\
\text { medium }\end{array}$ \\
\hline
\end{tabular}

TABle 8: Comprehensive correlation degree and grade of supply chain flexibility evaluation of each company.

\begin{tabular}{|c|c|c|c|c|c|}
\hline Company & I & II & III & IV & Grade \\
\hline A & -0.6301 & -0.5511 & -0.2380 & -0.0579 & $\begin{array}{c}\text { Transformation } \\
\text { to poor }\end{array}$ \\
\hline B & -0.2624 & 0.1675 & -0.3085 & -0.5014 & Good \\
\hline C & -0.4642 & -0.1924 & 0.0922 & -0.3065 & Medium \\
\hline $\mathrm{D}$ & -0.4932 & -0.3352 & -0.3536 & -0.1257 & $\begin{array}{c}\text { Transformation } \\
\text { to poor }\end{array}$ \\
\hline
\end{tabular}

degree of timely response and $c_{22}$ delivery flexibility is due to the company's relatively lagging response to market changes or changes in customer demand, the long time taken to respond to changes and uncertainties, the low sensitivity of delivery time, and the difficulty of shortening and changing the delivery service time at any time.

\section{Conclusion}

The development of each industry is faced with the uncertainty and risk brought by the external market environment. The flexibility level of the supply chain affects the market competitiveness and market position of enterprises. The results show that the improvement of supply chain flexibility depends on the efficient operation of the information system. Enterprises should find the information system suitable for their own business development needs, scientifically combine the business and data processing in actual work, realize the seamless connection between online and offline, and improve the ability of employees to use the information system and information platform. In addition, enterprises should balance the input of innovation resources. In addition to strengthening the innovation of product manufacturing technology, they should also pay attention to the sharing of information resources in the supply chain and strengthen the ability of obtaining internal and external information and identifying value information in the supply chain. In addition to the information system, the intelligent and high-tech service auxiliary equipment should also include the storage management and the provision of additional services in the customer waiting area. It is also very important to strengthen the cooperation with the internal and external enterprises of the supply chain. The enterprises in each link of the supply chain need to correctly handle the relationship between competition and cooperation, rationalize the division of labor, strengthen flexible cooperation, so as to jointly improve the ability to deal with market risks.

This paper designs a comprehensive and feasible evaluation system for supply chain flexibility research from the perspective of enterprise dynamic management and uses the matter-element evaluation method to effectively solve the problems of possible incompatibility of flexible indicators and multiobjective evaluation so that the evaluation results are more scientific and comprehensive, the key indicators affecting the evaluation results are more easily identified, and different evaluations of different research samples are made. The contrast and gap between the results are clearer. In the matterelement evaluation method, the construction of the matterelement extension evaluation model is the key to the research. The setting of classical domain and nodal domain and the design of correlation function have great room for improvement, which will be the future research direction.

\section{Data Availability}

The data used to support the findings of this study are available from the corresponding author upon request.

\section{Conflicts of Interest}

The authors declare that they have no conflicts of interest.

\section{Acknowledgments}

This work was supported by the Key Projects of the National Social Science Fund of China (no. 18AGL028).

\section{References}

[1] R. Srinivasan and M. Swink, "An investigation of visibility and flexibility as complements to supply chain analytics: an organizational information processing theory perspective," 
Production and Operations Management, vol. 27, no. 10, pp. 1849-1867, 2018.

[2] S. Fayezi, A. Zutshi, and A. O'Loughlin, "Understanding and development of supply chain agility and flexibility: a structured literature review," International Journal of Management Reviews, vol. 19, no. 4, pp. 379-407, 2017.

[3] Y. Jin, M. Vonderembse, T. S. Ragu-Nathan, and J. T. Smith, "Exploring relationships among IT-enabled sharing capability, supply chain flexibility, and competitive performance," International Journal of Production Economics, vol. 153, pp. 24-34, 2014.

[4] A. Rojo, J. Llorens-Montes, and M. N. Perez-Arostegui, "The impact of ambidexterity on supply chain flexibility fit," Supply Chain Management: An International Journal, vol. 21, no. 4, pp. 433-452, 2016.

[5] D. Eckstein, M. Goellner, C. Blome, and M. Henke, "The performance impact of supply chain agility and supply chain adaptability: the moderating effect of product complexity," International Journal of Production Research, vol. 53, no. 10, pp. 3028-3046, 2015.

[6] R. Sreedevi and H. Saranga, "Uncertainty and supply chain risk: the moderating role of supply chain flexibility in risk mitigation," International Journal of Production Economics, vol. 193, pp. 332-342, 2017.

[7] D. Simchi-Levi, H. Wang, and Y. Wei, "Increasing supply chain robustness through process flexibility and inventory," Production and Operations Management, vol. 27, no. 8, pp. 1476-1491, 2018.

[8] J. H. M. Manders, M. C. J. Caniëls, and P. W. T. Ghijsen, "Supply chain flexibility," The International Journal of Logistics Management, vol. 28, no. 4, pp. 964-1026, 2017.

[9] J. S. Kim, S. I. Park, and K. Y. Shin, "A quantity flexibility contract model for a system with heterogeneous suppliers," Computers \& Operations Research, vol. 41, pp. 98-108, 2014.

[10] R. Ishfaq and A. Narayanan, "Incorporating order-fulfillment flexibility in automotive supply chain through vehicle trades," Decision Sciences, vol. 50, no. 1, pp. 84-117, 2018.

[11] A. Rojo, M. Stevenson, F. J. Lloréns Montes, and M. N. PerezArostegui, "Supply chain flexibility in dynamic environments," International Journal of Operations \& Production Management, vol. 38, no. 3, pp. 636-666, 2018.

[12] A. K. Sahu, S. Datta, and S. S. Mahapatra, "Evaluation of performance index in resilient supply chain: a fuzzy-based approach," Benchmarking: An International Journal, vol. 24, no. 1, pp. 118-142, 2017.

[13] B. Singh Patel, C. Samuel, and S. K. Sharma, "Evaluation of agility in supply chains: a case study of an indian manufacturing organization," Journal of Manufacturing Technology Management, vol. 28, no. 2, pp. 212-231, 2017.

[14] S. Routroy, A. Bhardwaj, S. K. Sharma, and B. K. Rout, "Analysis of manufacturing supply chain agility performance using Taguchi loss functions and design of experiment," Benchmarking: An International Journal, vol. 25, no. 8, pp. 3296-3319, 2018.

[15] I. Kazemian and S. Aref, "Multi-echelon supply chain flexibility enhancement through detecting bottlenecks," Global Journal of Flexible Systems Management, vol. 17, no. 4, pp. 357-372, 2016.

[16] K. T. Shibin, A. Gunasekaran, T. Papadopoulos, R. Dubey, M. Singh, and S. F. Wamba, "Enablers and barriers of flexible green supply chain management: a total interpretive structural modeling approach," Global Journal of Flexible Systems Management, vol. 17, no. 2, pp. 171-188, 2016.
[17] R. Dubey, A. Gunasekaran, and S. J. Childe, "Big data analytics capability in supply chain agility: the moderating effect of organizational flexibility," Management Decision, vol. 57, no. 8, pp. 2092-2112, 2019.

[18] D. Ivanov, A. Das, and T.-M. Choi, "New flexibility drivers for manufacturing, supply chain and service operations," International Journal of Production Research, vol. 56, no. 10, pp. 3359-3368, 2018.

[19] G. Seebacher and H. Winkler, "A capability approach to evaluate supply chain flexibility," International Journal of Production Economics:manufacturing System Strategy Design, vol. 167, pp. 177-186, 2015.

[20] A. Chaudhuri, H. Boer, and Y. Taran, "Supply chain integration, risk management and manufacturing flexibility," International Journal of Operations \& Production Management, vol. 38, no. 3, pp. 690-712, 2018.

[21] A. R. Somarin, S. Asian, F. Jolai, and S. Chen, "Flexibility in service parts supply chain: a study on emergency resupply in aviation MRO," International Journal of Production Research, vol. 56, no. 10, pp. 3547-3562, 2018.

[22] W. Cai, Matter-element Analysis, Guangdong Higher Education Press, Guangdong, China, 1987.

[23] W. Cai, Matter-Element Model and Its Application, Science Press, Beijing, China, 1994.

[24] P. Y. Li, J. H. Wu, and H. Qian, "Groundwater quality assessment based on entropy weighted osculating value method," International Journal of Environmental Sciences, vol. 4, pp. 621-630, 2010. 